\title{
Carcinoma Mucoepidermóide de Tireóide: Relato de Caso e Revisão da Literatura
}

\author{
Sabrina R. França \\ Dayse Caldas \\ Alcebiades V. Junior \\ Carlos A.B. de Oliveiva
}

\begin{abstract}
RESUMO
O carcinoma mucoepidermóide é um tipo de neoplasia encontrada geralmente nas glândulas salivares, mamas, pâncreas e trato digestivo. O acometimento primário da glândula tireóide é muito raro, apenas 33 casos na literatura. Embora a maioria dos casos de carcinoma mucoepidermóide de tireóide (CMET) tenha evolução favorável, o caso clínico relatado descreve uma paciente com tumor agressivo e, a partir deste relato, é apresentada revisão da literatura quanto aos aspectos clínico, histopatológico, imunohistoquímico e origem histogenética dessa neoplasia. (Arq Bras Endocrinol Metab 2006;50/5:968-976)
\end{abstract}

Descritores: Carcinoma de tireóide; Carcinoma mucoepidermóide; Carcinoma mucoepidermóide primário da tireóide; Último corpo branquial

\section{ABSTRACT}

Mucoepidermoid Carcinoma of the Thyroid: A Case Report and Literature Review.

The mucoepidermoid carcinoma is a neoplasia that usually occurs at salivary glands, breast, pancreas and gastrointestinal tract. The primary occurrence on thyroid gland is rare and only 33 cases were previously published. Although the majority of cases of mucoepidermoid carcinoma of the thyroid (MECT) show a benign evolution, this paper describes a patient with an aggressive tumor. A literature review over clinical, histopathological, imunohistochemical features and histogenetic origin was discussed. (Arq Bras Endocrinol Metab 2006;50/5:968-976)

Keywords: Thyroid carcinoma; Mcoepidermoid carcinoma; Primary mucoepidermoid carcinoma of the thryroid; Ultimobranchial body

$\mathbf{O}$ CARCINOMA MUCOEPIDERMÓIDE PRIMÁRIO da tireóide (CMET) é uma neoplasia maligna muito rara, com apenas 33 casos relatados na literatura (1-20). A apresentação clínica inicial é de bócio uni ou multinodular atóxico, podendo haver comprometimento ganglionar ao diagnóstico. Não se observa localização preferencial quanto aos lobos e o comprometimento do istmo é muito raro, descrito em apenas um caso (2). Assim como em todas as condições patológicas tireoideanas, o sexo feminino é o mais acometido. A média de idade é de 40 anos, variando entre 10 a 83 anos. O prognóstico se mostra favorável na maioria dos casos, entretanto a associação com carcinoma papilífero e anaplásico pode contribuir para maior agressividade tumoral e pior prognóstico $(2,6,8,10,12,13,15)$. No relato atual, esta associação foi encontrada e pode explicar a agressividade e a rápida evolução da neoplasia. A base molecular dos CMET ainda é assunto controverso. Embora a maioria dos autores $(1-4,13,16)$ defenda a teoria dos ninhos sólidos de células (SCN) provenientes do último corpo branquial (UBB) como relacionada a histogênese dos CMET, outros
Recebido em 02/12/05
Aceito em 08/08/06 
(11,20,21) apresentam a hipótese de metaplasia das células foliculares como responsável pelo aparecimento neoplásico. A Organização Mundial de Saúde, em 2004, incluiu o CMET na classificação histológica dos tumores primários de tireóide, refletindo a raridade da doença, descrita desde 1977 (22).

\section{RELATO DO CASO}

Paciente feminina, 56 anos, branca, procurou assistência médica em novembro de 1996 com queixa de rouquidão, iniciada há seis meses. Relatava ter sido submetida a tiroidectomia parcial em 1971, devido a nódulos, mantendo-se assintomática, sem uso de hormônio tireoideano. Ao exame físico, apresentava tireóide aumentada de volume às custas de nódulo de aproximadamente $5 \mathrm{~cm}$ ocupando praticamente todo o lobo direito (LD), de consistência pétrea, sendo o lobo esquerdo (LE) grosseiramente irregular, com duas nodulações firmes e mal definidas. Ausência de linfonodomegalias. À ultrassonografia (US) revelava nódulos coalescentes no LD e parcialmente no istmo, medindo $3,5 \times 3,3 \times 4,0 \mathrm{~cm}$, com pequenas calcificações, e formação nodular sólida hipoecóica no terço médio do LE, de limites imprecisos e contornos irregulares, medindo $0,8 \times 0,9 \mathrm{~cm}$. O LE media $4,4 \times 1,3 \times 1,4 \mathrm{~cm}$. A cintilografia mostrava captação apenas na projeção do LE, com distribuição homogênea do traçador (captação de 24 hs de $30 \%$ ). Paralisia da corda vocal direita foi demonstrada pela laringoscopia direta e a esofagografia confirmava compressão da parede ântero-lateral direita da traquéia e do esôfago, com desvio contralateral dos mesmos. Exames hormonais: T4 livre 0,79 ng/dl, T4 total $6,8 \mathrm{mcg} / \mathrm{dl}$, T3 $135 \mathrm{ng} / \mathrm{dl}$, hormônio tireoestimulante (TSH) $2,1 \mathrm{mcU} / \mathrm{ml}$, anticorpo antimicrossomal (AAM) 1/100, anticorpo anti-tireoglobulina (AAT) $1 / 100$ e tireoglobulina (TG) $52,6 \mathrm{ng} / \mathrm{ml}$.

A paciente foi submetida à complementação de tiroidectomia total, em janeiro de 1997 . O relato intraoperatório mostrou LD totalmente aderido à musculatura adjacente, cuja biópsia de congelação sugeria neoplasia maligna sem definição do tipo histológico. Macroscopicamente, ao estudo histopatológico, a glândula apresentava superfície vermelho-acastanhada com cápsula espessada e consistência firme-elástica. Aos cortes, a formação maior era brancacenta, com áreas amareladas, de consistência amolecida, ao lado de outras de tonalidade acastanhada. À luz da microscopia, diagnóstico de neoplasia maligna de origem epitelial, com envolvimento do tecido gorduroso e da musculatura regional, além de invasão vascular, linfática e venosa foi confirmado. As características histopatológicas sugeriam possibilidade diagnóstica de carcinoma mucoepidermóide.

Procedeu-se então à realização de exames para afastar a possibilidade de carcinoma metastático para a tireóide, incluindo tomografia computadorizada de tórax e abdome, ultrassonografia de mamas, provas de função hepática, antígeno cárcino-embrionário (CEA), alfafetoproteína, CA-15.3, calcitonina, paratormônio e exames bioquímicos gerais, cujos resultados encontravam-se dentro do padrão de normalidade.

A revisão histopatológica confirmou tratar-se de neoplasia maligna de tireóide, com áreas de diferenciação papilífera e anaplásica. Verificam-se áreas neoplásicas de modelo papilífero, esboçando papilas com eixo conjuntivo, ao lado de células epiteliais atípicas anaplásicas. A neoplasia passa a apresentar áreas sólidas, com focos de necrose, evidenciando elementos do tipo epidermóide e outros com microvacuolização citoplasmática e vacúolos grosseiros configurando atividade secretora. O estudo histoquímico identificou em grupamentos epiteliais sólidos tanto a presença de mucina neutra (PÁS) quanto de mucina ácida (Alcian-Blue $\mathrm{pH}$ $2,5)$. Há ainda infiltrado linfóide e proliferação fibrosa em torno dos elementos tumorais, caracterizando quadro compatível com tireoidite de Hashimoto. Não se encontra infiltrado eosinofílico (figura 1).

A pesquisa de corpo inteiro (PCI), realizada no pós-operatório, revelou atividade iodocaptante correspondente ao LE da tireóide, sem evidências de imagem referentes a implantes secundários.

A paciente evoluiu, em 2 meses, com aumento de volume tireoideano, sinais flogísticos locais, disfagia e rouquidão rapidamente progressivos após tireoidectomia total, mensurados na palpação em $9 \mathrm{~cm}$ o LD e $6 \mathrm{~cm}$ o LE, de consistência pétrea, aderidos às estruturas do pescoço. Os exames hormonais desta ocasião eram: TSH 13,2 mcU/ml, T4T 8,7 mcg/dl, T4L $0,86 \mathrm{ng} / \mathrm{dl}$, TG 50,2 ng/ml, AAT $63 \mathrm{U} / \mathrm{ml}$, anti$\mathrm{TPO}<0,15 \mathrm{U} / \mathrm{ml}$ (ainda sem reposição de hormônios tireoideanos).

Optou-se pela realização da dose terapêutica (DT) com $\mathrm{I}^{131}(100 \mathrm{mCi}=3.700 \mathrm{Mbq})$, tendo em vista a captação loco-regional (LE) na PCI. O rastreamento oito dias após DT evidenciou tecido iodocaptante na topografia da região anterior, acima da cicatriz cirúrgica, mais intensamente à esquerda e em campos pulmonares, mais acentuado à direita. As demais áreas apresentavam-se sem anormalidades. Iniciou uso de hormônio tireoideano somente após a DT.

No entanto, o crescimento acelerado da lesão neoplásica manteve-se (LD $11 \mathrm{~cm}$ e LE $8 \mathrm{~cm}$ ), com 

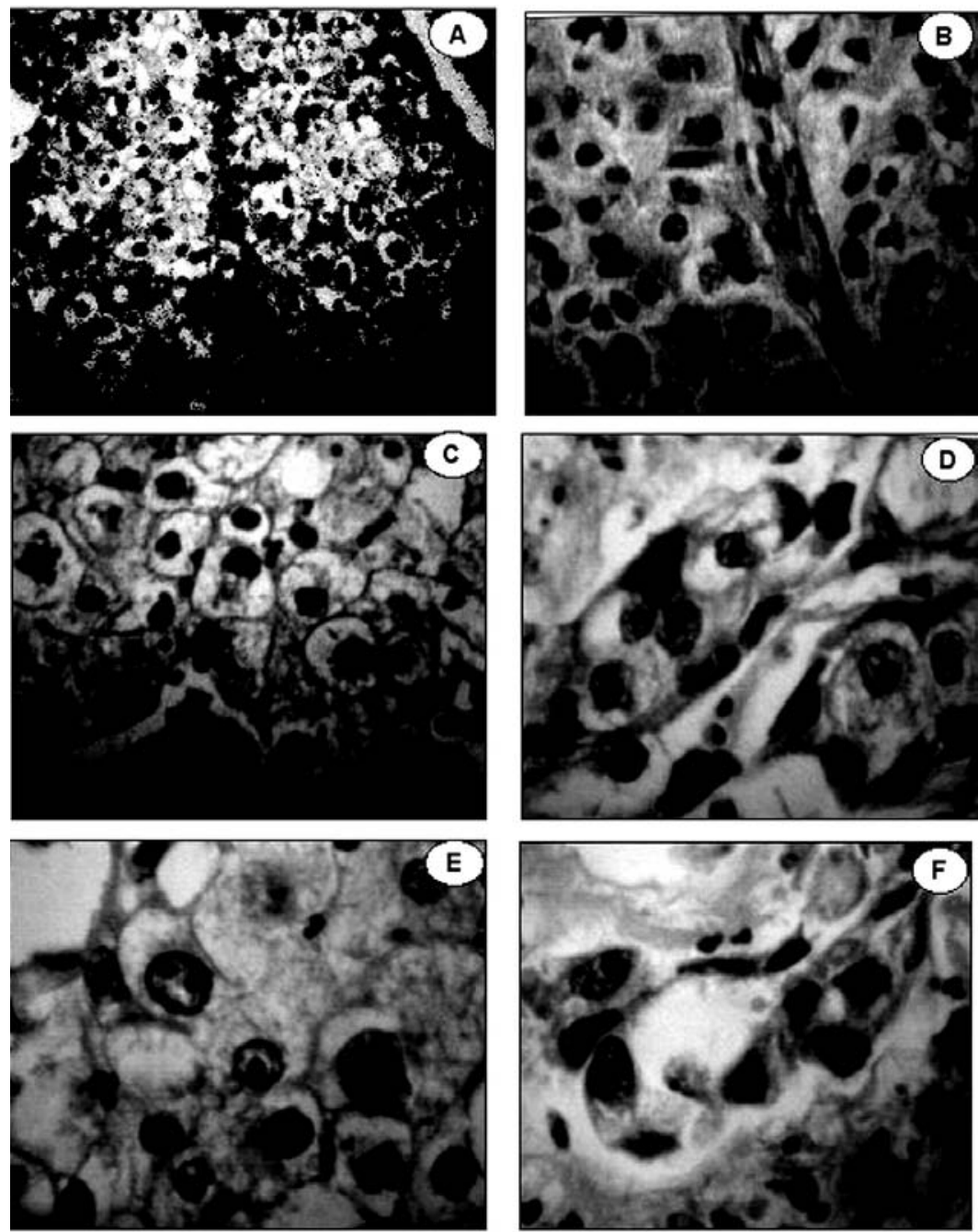

Figura 1. Histopatologia do Carcinoma Mucoepidermóide da Tireóide. Em A e B encontram-se áreas sólidas com células epiteliais atípicas, de diâmetros variáveis e particular hipercromatismo. Em C e D, os elementos celulares evidenciam ora citoplasma eosinófilo, com características escamosas, ora nítida vacuolização citoplasmática, basófila, de célula secretora abrigando mucina. Em maior aumento (E e F), observam-se tanto células escamosas quanto outras com produção de muco.

piora dos sintomas disfágicos, aparecimento de disfonia e perda de peso progressiva. A US cervical (maio/1997) evidenciou massa hipoecóica, heterogênea, com ecos internos em região anterior do pescoço, de maior volume à direita, apresentando baixa densidade (líquido espesso?) e focos hiperecóicos internos, com discreto reforço acústico posterior, situada em topografia da tireóide. A traquéia encontrava-se desviada para a esquerda pelo efeito compressivo extrínseco da massa. A tomografia computadorizada mostrou uma massa volumosa, ocupando toda a região anterior do pescoço, com invasão de estruturas vizinhas, determinando compressão das mesmas (figura 2). A paciente evoluiu com obstrução respiratória alta, necessitando de traqueostomia. Nessa época, ainda foram realizadas algumas sessões de radioterapia, porém sem obtenção de qualquer resposta terapêutica. A paciente veio a falecer cinco meses após o diagnóstico da neoplasia.

\section{REVISÃO DE LITERATURA}

\section{Aspectos clínicos, terapêuticos e prognósticos do CMET}

A revisão dos 33 casos de CMET descritos na literatura (tabela 1) mostra relação preferencial de 2:1 para o 

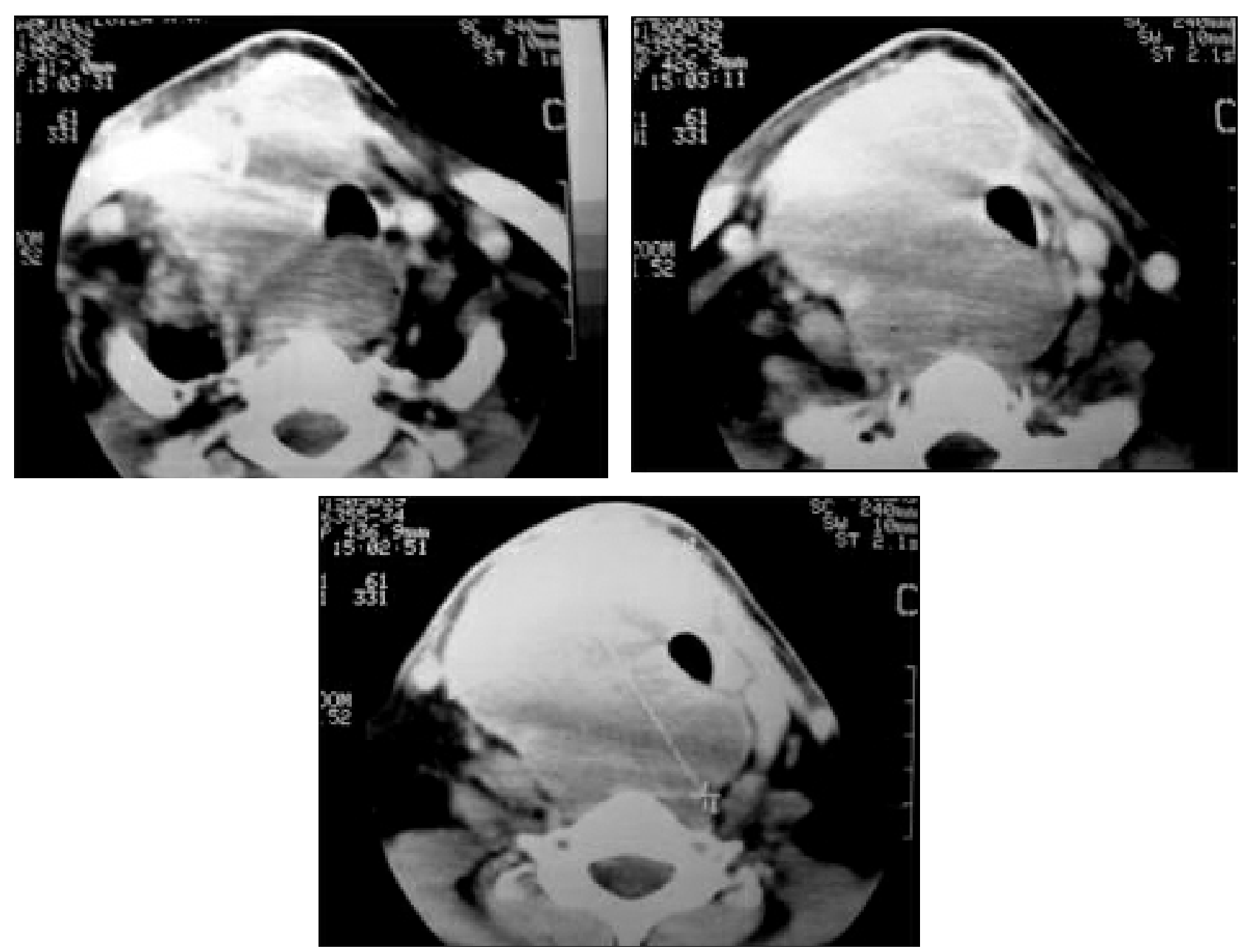

Figura 2. Tomografia computadorizada cervical mostra volumosa massa que invade estruturas vizinhas e desvia a traquéia para esquerda.

sexo feminino (22 mulheres e 11 homens), com idade média de acometimento aos 40 anos (mediana de 46 anos). A variação etária foi muito grande, comprometendo tanto crianças $(3 / 33$ casos com 10 e 1 lanos) quanto idosos $(7 / 33$ com idade $>60$ anos $)(2,3,10)$. $\mathrm{Na}$ apresentação clínica inicial, os pacientes mostramse eutiroideanos, com história de bócio uninodular (11 casos) $(2,5-7,10,13,16,18)$ ou multinodular ( 9 casos) $(1,2,4,5,8,11,12,14,15)$, sem preferência de lateralização ( 8 casos no lobo esquerdo, 13 no lobo direito e 11 casos sem menção de localização). Em apenas 1 paciente foi descrito comprometimento simultâneo do lobo direito e istmo (2). O tamanho do tumor é bastante variável (mediana de $2,5 \mathrm{~cm}$ ) com nódulos menores que $1 \mathrm{~cm}(2)$ e outros volumosos atingindo $10 \mathrm{~cm}$ no seu maior diâmetro (10), mostrando-se frios ou hipocaptantes em todos os casos em que a cintilografia foi mencionada.
O comportamento biológico do CMET é considerado pouco agressivo pela maioria dos autores. Em 14 casos, a malignidade se restringiu à tireoide (1-6,8$11,16)$, não havendo metástase regional cervical. Treze pacientes foram submetidos a tiroidectomia (parcial em 8 e total em 5 casos) com boa evolução. $\mathrm{O}$ tempo médio de follow-up foi de 52,7 meses (variando de 4 meses a 15 anos) e livres de recorrência. Em um caso não houve relato da terapêutica adotada (3).

Em 15 casos havia presença de metástase ganglionar ao diagnóstico inicial $(2,3,7,10,12-15,17,20)$, 8 dos quais foram submetidos a tiroidectomia parcial ou total. Não houve relato da conduta terapêutica em 5 pacientes (3). Em outros 2 casos $(15,20)$ foi realizado apenas rádio e/ou quimioterapia. Desses 15 casos com presença de metástase ganglionar ao diagnóstico, o prognóstico mostrou-se favorável em 5 deles $(2,3,7,11)$ que permaneciam vivos após um período 
Tabela 1. Aspectos clínicos, terapêuticos e prognóstico dos CMET citados na literatura.

\begin{tabular}{|c|c|c|c|c|c|c|c|c|}
\hline Autor & $\begin{array}{l}\text { Idade/ } \\
\text { Sexo }\end{array}$ & $\begin{array}{l}\text { Tamanho } \\
(\mathrm{cm})\end{array}$ & $\begin{array}{l}\text { Localização } \\
\text { no lobo }\end{array}$ & $\begin{array}{c}\text { Extensão } \\
\text { extra } \\
\text { capsular }\end{array}$ & $\begin{array}{l}\text { Metástases ao } \\
\text { Diagnóstico }\end{array}$ & $\begin{array}{l}\text { Restante } \\
\text { Glandular }\end{array}$ & $\begin{array}{l}\text { Tratamento/ } \\
\text { Recorrência }\end{array}$ & Follow-up \\
\hline Fialho' & $47 / M$ & 2,7 & Esquerdo & Não & Não & $\begin{array}{l}\text { TH e nódulo } \\
\text { colóide }\end{array}$ & TS/ Não & Vivo 20 meses \\
\hline Franssila $^{2}$ & $25 / \mathrm{F}$ & 2,5 & Esquerdo & Não & Não & Normal & T/ Met. nodal 7 meses após & Vivo 1 ano e 5 \\
\hline & & & & & & & TT, Rłx / não & meses \\
\hline Franssila ${ }^{2}$ & $10 / \mathrm{F}$ & 0,8 & Esquerdo & Não & Nodal bilateral & TL & T, Linfadenectomia, Rtx, e & Vivo 10 meses \\
\hline Franssila $^{2}$ & $54 / \mathrm{F}$ & & $\begin{array}{l}\text { Direito e } \\
\text { istmo }\end{array}$ & Sim & $\begin{array}{l}\text { Nodal supraclavi- } \\
\text { cular e cervical }\end{array}$ & $\begin{array}{l}\text { PTC e Ca. } \\
\text { anaplásico }\end{array}$ & $\begin{array}{l}\text { Qtx/ Met. nodal } 5 \text { meses } \\
\text { após }\end{array}$ & $\begin{array}{l}\text { Óbito } 1 \text { ano e } 8 \\
\text { meses }\end{array}$ \\
\hline Sobrinho Simões ${ }^{3}$ & $11 / \mathrm{F}$ & & & & Nodal & $\mathrm{TL}$ & & \\
\hline Sobrinho Simões ${ }^{3}$ & $20 / F$ & & & & Nodal & $\mathrm{TL}$ & $\begin{array}{l}\text { ?/ Met. pulmonar } 7 \text { anos } \\
\text { mais tarde }\end{array}$ & $\begin{array}{c}\text { Vivo com met. } 22 \\
\text { anos }\end{array}$ \\
\hline Sobrinho Simões ${ }^{3}$ & $67 / \mathrm{F}$ & & & & Nodal & $\mathrm{TL}$ & $\begin{array}{l}\text { ?/ Met. nodal } 2 \text { e } 3 \text { anos } \\
\text { mais tarde }\end{array}$ & \\
\hline Sobrinho Simões ${ }^{3}$ & $11 / \mathrm{M}$ & & & & Nodal & TL & $\begin{array}{l}\text { ?/ Met. nodal } 1 \text { ano mais } \\
\text { tarde }\end{array}$ & $\begin{array}{l}\text { Vivo com met. } 5 \\
\text { anos }\end{array}$ \\
\hline Sobrinho Simões ${ }^{3}$ & $58 / \mathrm{F}$ & & & & Nodal & TL & & Óbito 10 dias \\
\hline Sobrinho Simões ${ }^{3}$ & $15 / \mathrm{M}$ & & & & Não & TL & ?/ Não & Vivo 6 meses \\
\hline Katoh $^{4}$ & $56 / F$ & 1,0 & Esquerdo & Não & Não & $\begin{array}{l}\text { TL e adenoma } \\
\text { folicular }\end{array}$ & TS, linfadenectomia/ Não & Vivo 8 meses \\
\hline Wenig $^{5}$ & $46 / M$ & 3,5 & Direito & Sim & Não & $\begin{array}{l}\text { TL, nódulos adeno- } \\
\text { mato-sos e PTC }\end{array}$ & TS/ Não & Vivo 15 anos \\
\hline Wenig $^{5}$ & $52 / \mathrm{M}$ & 2,0 & Direito & Não & Não & $\mathrm{TL}$ & TS/ Não & Vivo 13 anos \\
\hline Wenig $^{5}$ & $29 / F$ & 2,3 & Direito & Não & Não & TL & TS/ Não & $\begin{array}{c}\text { Vivo } 1 \text { ano e } 6 \\
\text { meses }\end{array}$ \\
\hline Bondenson 6 & $35 / \mathrm{F}$ & 2,0 & Direito & Sim & Não & $\begin{array}{l}\text { Áreas de diferenci- } \\
\text { ação papilífera }\end{array}$ & $\begin{array}{l}\text { TS, linfadenectomia/ Met. } \\
\text { nodal após } 1 \text { ano (feito Rtx); } \\
\text { pulmonar após } 5 \text { anos; } \\
\text { recorrência para pescoço } \\
\text { após } 7 \text { anos (feito DT } 1131 \\
1200 \mathrm{mCl} \text { ) }\end{array}$ & $\begin{array}{c}\text { Vivo com met. } 12 \\
\text { anos }\end{array}$ \\
\hline Roberto Miranda 7 & $29 / \mathrm{F}$ & 2,8 & Direito & Sim & Nodal cervical & PTC & TS, linfadenectomia & Vivo 9 meses \\
\hline Rhatigan $^{8}$ & $20 / F$ & 2,0 & Esquerdo & Não & Não & $\begin{array}{l}\text { TL, adenoma foli- } \\
\text { cular, PTC }\end{array}$ & TT/ Não & $\begin{array}{c}\text { Vivo } 1 \text { ano e } 6 \\
\text { meses }\end{array}$ \\
\hline Tanda $^{9}$ & $33 / \mathrm{M}$ & 6,0 & Direito & Não & Não & & TS/ Não & Vivo 4 meses \\
\hline Baloch10 & $27 / \mathrm{F}$ & & & Não & Não & Normal & $\pi$ & Vivo 7 anos \\
\hline Baloch $^{10}$ & $64 / \mathrm{M}$ & 2,0 & Direito & Sim & Nodal cervical & PTC & TS e TT & Óbito 3 meses \\
\hline Baloch $^{10}$ & $83 / \mathrm{M}$ & 10,0 & Direito & Sim & Pulmão & Ca anaplásico & TS & Óbito 5 meses \\
\hline Baloch $^{10}$ & $55 / \mathrm{M}$ & & & & & Normal & $\pi$ & Vivo 7 anos \\
\hline Baloch 10 & $36 / \mathrm{F}$ & 1,6 & Esquerdo & Não & Não & TL & $\pi$ & \\
\hline Stelle ${ }^{11}$ & $63 / \mathrm{F}$ & 3,3 & Esquerdo & Sim & Não & TL & TT/ Não & Vivo 10 meses \\
\hline Arezzo $^{12}$ & $66 / \mathrm{M}$ & 3,4 & Esquerdo & Sim & Nodal & TH e PTC & $\begin{array}{l}\text { TS, linfadenectomia, Rtx e DT } \\
1131\end{array}$ & Óbito 11 meses \\
\hline Cammesell13 & $62 / \mathrm{F}$ & 3,0 & Direito & Sim & Nodal cervical & $\begin{array}{l}\text { PTC e Ca } \\
\text { anaplásico }\end{array}$ & $\pi$, linfadenectomia & Óbito 10 meses \\
\hline Viciana $^{14}$ & $45 / \mathrm{M}$ & & Direito & & Nodal cervical & $\begin{array}{l}\text { Áreas de diferenci- } \\
\text { ação papilífera }\end{array}$ & Tா/ Não & \\
\hline Ramirez 15 & $57 / \mathrm{M}$ & & & & Nodal & Ca anaplásico & QTX & Óbito 2 meses \\
\hline Misukami16 & $44 / \mathrm{F}$ & 7,0 & Direito & Sim & Não & & $\begin{array}{c}\text { TS, linfadenectomia/ Met. } \\
\text { nodal } 10 \text { meses após }\end{array}$ & $\begin{array}{c}\text { Vivo } 1 \text { ano e } 8 \\
\text { meses }\end{array}$ \\
\hline Harach 17 & $18 / \mathrm{M}$ & 1,2 & Direito & Não & Nodal & $\mathrm{TL}$ & $\pi$, R+x/ não & Vivo 11 meses \\
\hline Larson 18 & $61 / F$ & ?Grande & Direito & Sim & $\begin{array}{c}\text { Pulmonar e verte- } \\
\text { bral }\end{array}$ & & Rtx, Qtx/ Não & \\
\hline Jayarom $^{19}$ & $46 / \mathrm{M}$ & & & & & & Qtx/ recorrência cervical & \\
\hline Minigawa ${ }^{20}$ & $52 / F$ & & & & $\begin{array}{l}\text { Nodal, vertebral, } \\
\text { pulmonar }\end{array}$ & & Rtx e Qtx & Óbito 2 meses \\
\hline
\end{tabular}

F: feminino; M: masculino; TT: tiroidectomia total; TS: tiroidectomia subtotal; TL: tiroidite linfocítica; TH: tiroidite de Hashimoto; PTC: carcinoma papilífero; Qtx: quimioterapia; Rtx: radioterapia; DT: dose terapêutica; 1131: iodo radioativo; CMET: carcinoma mucoepidermóide de tireóide. 
médio de acompanhamento de 70 meses (variação de 9 meses a 22 anos). No entanto, também foram observados 6 óbitos $(2,3,10,12,13,15), 5$ dos quais $(2,10,12,13,15)$ apresentavam associação do CMET com carcinoma papilífero e anaplásico.

Em apenas 3 dos 33 casos descritos $(10,18,20)$ houve presença de metástase a distância (pulmonar e/ou vertebral) ao diagnóstico. Dois deles evoluíram para óbito, um dos quais ( 5 meses após tiroidectomia subtotal) apresentava carcinoma anaplásico associado (10).

Ressaltamos a importância da presença de áreas de diferenciação anaplásica e papilífera com o prognóstico desfavorável do CMET. Em $75 \%$ dos casos de óbito ( 6 dos 8 pacientes) houve presença dessa associação. No relato atual, este achado pode explicar a agressividade e a rápida evolução da neoplasia.

\section{Aspectos histopatológicos e imunohistoquímicos do CMET}

O carcinoma mucoepidermóide (CME) é caracterizado por conter três tipos de células: células secretoras, epidermóides e intermediárias, estas últimas também chamadas de basais ou transicionais. Os CME são classificados em três grupos que se relacionam com seu valor prognóstico; bem diferenciado ou de baixo grau de malignidade, moderadamente diferenciado ou de grau intermediário de malignidade e pouco diferenciado ou de alto grau de malignidade (1).

O CMET, macroscopicamente se apresenta como uma neoplasia de limites mal definidos, não encapsulado, sólido, homogêneo, de tamanhos variados. Microscopicamente, as características histopatológicas se assemelham com aquelas descritas para o carcinoma mucoepidermóide em geral; neoplasia epitelial maligna composta por células mucosas e escamosas. As células escamosas formam normalmente estruturas sólidas, concêntricas, onde é habitual a produção de ceratina individualmente pela célula, ou por grupo de células, com desenvolvimento de pérolas córneas $(1,23)$. As células mucosas são cuboidais ou esféricas, tendendo a formar estruturas císticas ou podendo se arranjar em estruturas mais sólidas. A quantidade de mucina é variável. O citoplasma destas células é abundante com aspecto claro ou espumoso, positivo para histoquímicos como o mucicarmina e Alcian-Blue ph 2,5. O núcleo se localiza perifericamente. Pleomorfismo nuclear moderado e figuras de mitose esparsas são freqüentemente encontradas, variando em freqüência de acordo com a classificação prognóstica do tumor. A microscopia eletrônica revela, por sua vez, presença de tonofilamentos e desmosomas nas células escamosas e inúmeros grânulos de mucina nas células mucosas. O estroma é denso com produção de colágeno e fibras reticulares, contendo infiltrado celular misto, composto predominantemente de linfócitos ou, em alguns casos, de eosinófilos $(1,4,15,16)$. A infiltração eosinofílica é mais comum nos casos de Carcinoma Mucoepidermóide Esclerosante de Tireóide com Eosinofilia (SMECE), outro tipo de neoplasia primária também rara de tireóide, considerada por alguns autores (24) como subtipo do CMET, mas por outros (10) como uma neoplasia de origem e características distintas do CMET.

Em relação à imunohistoquímica, estudos mostram diferentes resultados de acordo com os marcadores utilizados. Em geral, os CMET são positivos para ceratina e antígeno cárcino-embrionário (CEA). Os autores que utilizaram marcadores neuroendócrinos demonstraram positividade destes marcadores na maioria dos casos $(2,8,13)$. Os resultados com o marcador tireoglobulina (TG) foram divergentes: a maioria dos estudos mostrou negatividade para este marcador nos tumores mucoepidermóides $(2,4,10,12,15$, $17,18,20,23)$. No entanto, em alguns casos, numa mesma amostra ocorreu positividade para TG nas células foliculares não envolvidas pela neoplasia e negatividade nas células realmente comprometidas (5). Mais raramente alguns tumores apresentaram reatividade para este marcador, inclusive nas células neoplásicas $(8-10,13,14)$.

Hipóteses histogenéticas para origem do CMET A histogênese do CMET ainda permanece em controvérsia. Embora a maioria dos autores concorde com a hipótese da origem a partir do último corpo branquial (UBB) $(1-4,11,13,16,20,25)$, há outros que discordam, enfatizando a idéia de que na verdade esses tumores se originariam das próprias células foliculares (5-7). Os autores, que acreditam que o CMET se origine dos ninhos sólidos de células (SCN) derivados do UBB, mostram semelhanças histológicas, histoquímicas e imunohistoquímicas entre eles $(2,3,11,20,25)$. Aqueles que não apóiam esta hipótese admitem que, embora existam algumas semelhanças, estas não seriam totalmente suficientes para excluir a possibilidade de o CMET originar-se das células foliculares da tireóide. A hipótese de tecido de glândula salivar ectópico como origem do CMET, inicialmente proposta por Rhatigan e col. em 1977 (8), que foram os primeiros a relatar esse tipo de neoplasia de tireóide, foi refutada pelo estudo de Fialho e Basílio, 1981 (1). Wenig e col. (5) descreveram seis casos de CMET positivos para TG e nem todos reativos para os marcadores neuroendócrinos, e reforçam a idéia de que a origem do 
CMET a partir do UBB, apesar de defendida pela maioria dos pesquisadores, ainda seria questionável, destacando para isso além dos achados imunohistoquímicos vários aspectos clínicos e histopatológicos que reforçariam esta idéia. Um aspecto histológico que contraria a teoria do SCN como origem dos CMET é a ausência de queratinização e pontes intercelulares no SCN, achados histológicos clássicos deste tipo de tumor (CMET) (10).

Entre os dados que favorecem a hipótese do UBB como origem dos CMET, estão os estudos imunohistoquímicos, alguns mostrando positividade de $100 \%$ para marcadores confiáveis de células do SCN, como por exemplo o antígeno carcinoembrionário (CEA) e citoqueratina (CK) nas células tumorais. Estes mesmos estudos mostram negatividade para tireoglobulina (TG) e calcitonina (CT), embora algumas células- $\mathrm{C}$ isoladas se mostrassem positivas para este último marcador (20).

Wenig e col. (5) questionam o achado de CMET no istmo da glândula tireóide, o que não corresponderia à localização anatômica do SCN (localizados embriologicamente no terço médio e superior das laterais dos lobos). Ainda nesta mesma publicação, sugerem que a presença da tireoidite linfocítica no restante da glândula não neoplásica seria possível indutora de metaplasia escamosa das células foliculares, podendo gerar foco potencial para subseqüente desenvolvimento de neoplasias de células foliculares, incluindo o carcinoma mucoepidermóide e o carcinoma escamoso (5).

A coexistência de CMET e PTC é importante observação a ser destacada. Embora não se possa estabelecer uma conexão específica entre os dois tipos de tumores, alguns autores $(6,14)$ afirmam que este achado não deva ser considerado apenas uma coincidência. Há vários relatos descritos na literatura que provam a coexistência de CMET e PTC $(2,7,10,12-14)$. Estes dois tipos de tumores apresentam características em comum como presença de fibrose intramural, corpos psamomatosos, reatividade para tireoglobulina e metástases preferenciais para linfonodos (5). Por acreditarem que os remanescentes do UBB (que seriam os $\mathrm{SCN}$ ) poderiam dar origem não só às células parafoliculares mas também a um contingente de células foliculares, Cameselle-Teijeiro e col. (26) afirmam que as células tronco do UBB (stem cells) estariam envolvidas na origem histogenética de vários tipos de carcinomas de tireóide, dentre eles o PTC e o CMET. Na opinião desses autores (26), o CMET, se originando das células tronco do UBB, poderia adquirir em áreas diferenciadas nítido padrão primitivo do tipo intestinal (noncommitted) ao invés dos padrões do tipo endócrino ou neuroendócrino (committed), que seriam os mais comuns, podendo conter, portanto, algumas áreas de diferenciação escamosa, mucosa, ciliada, ou mesmo folicular no mesmo tipo tumoral (8). Desta forma, o padrão imunohistoquímico dependeria da origem e diferenciação das células primitivas, podendo haver ou não reatividade para tireoglobulina em alguns casos de CMET, assim como para marcadores neuroendócrinos. Esta hipótese também explicaria os achados de coexistência na mesma neoplasia, de PTC e CMET nos casos de Wenig (5), além dos achados imunohistoquímicos controversos (falta de reatividade para marcadores neuroendócrinos em alguns e reatividade para tireoglobulina em outros casos de CMET).

\section{DISCUSSÃO}

Destacamos o fato de a paciente apresentar, após a cirurgia (enquanto aguardava exames de imagem para afastar metástase tireoideana de neoplasia mucoepidermóide de outro sítio e realização de PCI), níveis de $\mathrm{TSH}$ pouco elevados $(13 \mathrm{mcU} / \mathrm{ml})$ e de tiroxina dentro da normalidade (T4T $8,7 \mathrm{mcg} / \mathrm{dl} \mathrm{e}$ T4L 0,86 $\mathrm{ng} / \mathrm{dl}$ ), quando, na verdade, esperaríamos níveis superiores de TSH e níveis bem mais baixos de T4, já que a paciente estava sem reposição hormonal com levotiroxina há dois meses e havia sido operada por equipe cirúrgica experiente (o que nos garantia a segurança de tiroidectomia quase total). Além disso, os níveis de tireoglobulina (TG) também se mostraram elevados no pós-operatório $(50 \mathrm{ng} / \mathrm{ml})$, o que indicava a presença de fonte produtora. A pesquisa de corpo inteiro (PCI) realizada 40 dias após a cirurgia confirmou atividade tecidual tireoideana com captação de $30 \%$, sugerindo recidiva e crescimento rápido de tecido tumoral iodo-captante ou área de tecido tireoideano remanescente ou ambas as possibilidades, apesar da excelência da equipe cirúrgica.

As revisões anatomopatológica e histoquímica confirmaram carcinoma mucoepidermóide com destaque de áreas com diferenciação papilífera e anaplásica. Desta forma, questionamos se a fonte produtora de TG seria ou não, devido às áreas de carcinoma papilífero (PTC), encontradas na neoplasia. A captação loco-regional e, principalmente, pulmonar observadas na cintilografia pós-dose terapêutica sugerem carcinoma papilífero recidivado, pois a possibilidade de tratar-se do componente mucoepidermóide da neoplasia seria remota, já que este tumor se mostrou hipocaptante. É sabido que as células tumorais dos carcinomas diferenciados (PTC) são produtoras de 
TG e mantêm capacidade de captação do radioiodo (princípio pelo qual a PCI torna-se um exame útil para rastreamento de metástase neste tipo de neoplasia). Entretanto, quanto ao CMET, não há certeza sobre a capacidade de produção de TG pelas células tumorais, nem se essas células sejam capazes de captar o radioiodo. De acordo com os casos levantados na literatura, houve positividade para TG em $41 \%$ deles, nos quais esse marcador foi utilizado na análise imunohistoquímica (1-20).

A opção pelo radioiodo não se mostrou uma terapia eficaz, pois não houve controle adequado do crescimento tecidual no leito tireoideano. A ultrassonografia cervical realizada um mês depois já mostrava massa heterogênea de conteúdo semelhante a líquido espesso, o que poderia sugerir produção de mucina pelas células mucoepidermóides. Estes resultados levam a crer que o próprio CMET ou as áreas anaplásicas associadas seriam responsáveis pela recidiva, não sendo iodo-sensível como seria esperado no caso de carcinoma papilífero.

As dúvidas sobre a origem do carcinoma mucoepidermóide (se primário ou secundário), a raridade desse tipo de neoplasia primariamente na tireóide e conseqüentemente maior conhecimento do comportamento biológico da neoplasia, suscitam dúvidas quanto ao pertinente procedimento terapêutico. Em 1997 (época do diagnóstico do presente caso), apenas Franssila e col. (2) e Cammeselle-Teijeiro e col. (13) haviam relatado associação concomitante de CMET com o PTC e carcinoma anaplásico. Esses autores optaram por condutas terapêuticas diferentes (tabela 1 ). Ressaltamos, na revisão atual, que $75 \%$ dos casos de óbito (6 entre 8 pacientes) por CMET estavam associados com o PTC e/ou com carcinoma anaplásico $(2,10$, $12,13,15)$.

Destacamos também a possibilidade da presença de carcinoma mucoepidermóide na ocasião da primeira tireoidectomia (parcial) em 1971, pois não conseguimos acesso ao laudo histopatológico, nem às lâminas desta época, esclarecendo o diagnóstico. A neoplasia poderia ter tido um longo curso favorável e recidivado após 20 anos.

Afasta-se a possibilidade de Carcinoma Mucoepidermóide Esclerosante de Tireóide com Eosinofilia (SMECE) pela ausência de estroma denso com infiltração eosinofilica intensa, que é a principal diferença histopatológica deste tipo de neoplasia com o CMET (figura 1). No entanto, ambos apresentam componentes escamoso (porém com formações mais sólidas e maiores ninhos de células no CMET), secretor (células mucosas mais evidentes com espaços císticos no CMET e menor quantidade com menor volume no SMECE) e parênquima com tiroidite linfocítica ou tiroidite de Hashimoto $(1,2-8,10,12,17,24)$.

A importância do caso deve-se não só à raridade deste tipo de neoplasia, mas também à evolução adversa já que o CMET é considerado, em sua maioria, neoplasia de comportamento biológico pouco agressivo.

\section{REFERÊNCIAS}

1. Fialho F, Basilio-de-Oliveira CA, Azevedo N, Rocha Filho AF. Carcinoma mucoepirdermóide da tireóide. F Med (BR) $1981 ; 82: 397-402$.

2. Franssila KO, Harach HR, Wasenius VM. Mucoepidermoid carcinoma of the thyroid. Histopathology 1984; 8:847-60.

3. Sambade C, Franssila K, Basilio de Oliveira CA, Sobrinho Simões M. Mucoepidermoid carcinoma of the thyroid revisited. Surg Pathol 1990;3:271-80.

4. Katoh R, Sugai T, Ono S, Takayama K, Tomichi N, Kurihara $\mathrm{H}$, et al. Mucoepidermoid carcinoma of the thyroid. Cancer 1990;65:2020-7.

5. Wenig BM, Adair CF, Heffess CS. Primary mucoepidermoid carcinoma of the thyroid gland: a report of six cases and a review of the literature of a follicular epithelial-derived tumor. Hum Pathol 1996;26:1099-108.

6. Bondeson L, Bondeson AG, Thompson NW. Papillary carcinoma of the thyroid with mucoepidermoid features. Am J Clin Pathol 1990:95:175-9.

7. Miranda R, Myint MA, Gnepp DG. Composite follicular variant of papillary carcinoma and mucoepidermoid carcinoma of the thyroid. Report of a case and review of the literature. Am J Surg Pathol 1995; 19:1209-15.

8. Rhatigan RM, Raque JL, Bucher RL. Mucoepidermoid carcinoma of the thyroid gland. Cancer 1977;39:210-49.

9. Tanda F, Massarelli G, Bosincu L. Primary mucoepidermoid carcinoma of the thyroid gland. Surg Pathol 1990;3:317-24.

10. Baloch ZW, Solomon BS, Livolsi VA. Primary mucoepidermoid carcinoma and sclerosing mucoepidermoid carcinoma with eosinophilia of the thyroid gland: a report of nine cases. Modern Pathol 2000; 13:802-7.

11. Steele SR, Royer M, Brown TA, Porter C, Azarow KS. Mucoepidermoid carcinoma of the thyroid gland: a case report and suggested surgical approach. Am Surg 2001;67:979-83.

12. Arezzo P, Patetta R, Ceppa P, Borgonovo G, Torre G, Matitioli FP. Mucoepidermoid carcinoma of the thyroid gland arising from a papillary epithelial neoplasm. Am Surg 1998;64:307-11.

13. Cameselle-Teijeiro J, Perez F, Sobrinho Simões M. Papillary and mucoepidermoid carcinoma of the thyroid with anaplastic transformation. A case report with histological and immunohistochemical findings that support a provocative histogenetic hypothesis. Pathol Res Pract 1995; 191:1214-21. 
14. Viciana MJ, Davidson HG, Lacave IM, Segura DI, Loizaga JM. Papillary carcinoma of the thyroid with mucoepidermoid differentiation. Arch Pathol Lab Med $1996 ; 120: 397-8$

15. Ramírez FV, Salaverri CO, Manzano OA, Ruiz HG, Campora RG. Fine needle aspiration cytology of high-grade mucoepidermoid carcinoma of the thyroid. A case report. Acta Cytologica 2000;44:259-64.

16. Mizukami Y, Matsubara F, Hashimoto T, Haratake J, Terahata S, Noguchi M, et al. Primary mucoepidermoid carcinoma in the thyroid gland: a case report including ultrastructural and biochemical study. Cancer 1984:53:1741-5

17. Harach HR. Mucoepidermoid carcinoma of the thyroid: a report of a case with immunohistochemical studies. Medicina (B. Aires) 1986;46:313-16.

18. Larson RS, Wick MR. Primary mucoepidermoid of the thyroid: diagnosis by fine needle aspiration biopsy. Diag Cytopathol 1992;9:438-43.

19. Joyaram G, Jalalidim MA. Mucoepidermoid carcinoma of the thyroid: a case report. Malays J Pathol 1998;20:45-8.

20. Minagawa A, Litaka M, Suzuki M, Shimada S, Kitahama S. Wada $S$, et al. A case of primary mucoepidermoid carcinoma of the thyroid: molecular evidence of its origin. Clin Endocrinol 2002;57:551-6.

21. Mizukami Y, Nonomura A, Michigishi T, Noguchi M, Hashimoto T, Nakamura S, et al. Solid cell nests of the thyroid. A histologic and immunohistochemical study. Am J Clin Pathol 1994;101:186-91.
22. Cameselle-Teijeiro J, Wenig BM, Sobrinho-Simões $M$, Albores-Saavedra J. Mucoepidermoid Carcinoma. In: DeLellis RA, Lloyd RV, Heitz PU, Eng C, eds. Pathology \& genetics tumors of endocrine organs. Lyon: IARC Press, 2004. pp. 82-3.

23. Harach HR. Solid cells nests of thyroid. J Pathol 1988; 155; 191-200.

24. Chan JKC, Albores-Saavedra J, Battifora H, Carcangiu ML, Rosai J. Sclerosing mucoepidermoid thyroid carcinoma with eosinophilia. A distinctive low-grade malignancy arising from the metaplastic follicles of Hashimoto's thryroiditis. Am J Surg Pathol 1991;15;438-48.

25. Ingbar HS, Lewis EB. Normal development of the hypothalamic-pituitary-thryroid axis: Ontogeny of the neuroendocrine unit. The thyroid - A fundamental and clinical text. $5^{\text {th }}$ ed. Philadelphia: J.B. Lippincott Co.; 1986. pp. 7-22.

26. Cameselle-Teijeiro J, Varela Duron J, Sambade C, Villanueva JP, Varela Nunez R, Sobrinho Simões M. Solid cell nests of the thyroid: light microscopy and immunohistochemical profile. Hum Pathol 1994;25:684-93.

\section{Endereço para correspondência:}

Dayse Caldas

Rua Conde de Bonfim 370, sala 502

20520-054 Rio de Janeiro, RJ

E-mail: daysecaldas@superig.com.br 